\title{
ANTI-PROLIFERATIVE ACTIVITY OF ZIZYPHUS SPINA CHRISTI LEAVES METHANOL EXTRACT AGAINST RHABDOMYOSARCOMA (RD) CELL LINE
}

\author{
AHMED R. ABU-RAGHIF1, GHAITH A. JASIM², MUNEER M. HANOON³
}

1Al-Nahrain University/College of Medicine/Pharmacology Department, Baghdad-Iraq, ${ }^{2}$ Al-Mustansiriyah University/College of Pharmacy/Department of Pharmacology and Toxicology, Baghdad-Iraq, ${ }^{3}$ Thi Qar Health Office/Thi Qar Poison Control Center Email: mmhanoon82@yahoo.com

Received: 02 Sep 2016 Revised and Accepted: 29 Dec 2016

\section{ABSTRACT}

Objective: The aim of this study was to investigate the capability of Zizyphus spina christi methanol extract to inhibit cancer cell line proliferation.

Methods: The leaves of Zizyphus spina christi were extracted by cold maceration method. The anti-proliferative activity of the methanol extract against rhabdomyosarcoma (RD) cell line was tested by 3-(4, 5 Dimethylthiazol-2yl)-2,5-diphenyltetrazolium bromide (MTT) assay. The phytochemical constituents were identified by gas chromatography-mass spectrometry (GC-MS) analysis. The antioxidant activity was assessed by measuring free radical scavenging activity using 1,1-diphenyl-2-picrylhydrazyl (DPPH) assay.

Results: The percentage extraction yield for leaves with methanol was $20.64 \%$. The methanol extract showed dose dependent inhibition of RD cell line, the IC 50 was $154.44 \mu \mathrm{g} / \mathrm{ml}$. GC-MS showed the presence of flavonoid fraction and other compounds with antioxidant activity. The methanol extract demonstrated DPPH scavenging activity with $\mathrm{IC}_{50}$ of $33.91 \mathrm{mg} / \mathrm{ml}$.

Conclusion: Methanol extract showed potential anti-proliferative activity against RD cell line, which could be due to its antioxidant activity.

Keywords: Anti-proliferative activity, Zizyphus spina christi, Methanol extract, RD cell line, MTT assay, DPPH assay

(c) 2017 The Authors. Published by Innovare Academic Sciences Pvt Ltd. This is an open access article under the CC BY license (http://creativecommons.org/licenses/by/4. 0/) DOI: http://dx.doi.org/10.22159/ijpps.2017v9i2.15013

\section{INTRODUCTION}

Cancer is one of the most leading causes of mortality in the world, accounting for almost $13 \%$ of deaths worldwide [1]. Cancer is characterized by uncontrolled growth of abnormal cells, which have the ability to invade other tissues and metastasize to other parts of the body via blood and lymph [2].

Rhabdomyosarcoma (RMS) is a malignancy that arises from skeletal muscle precursors [3]. It is the most common type of soft tissue sarcoma in children and adolescents less than twenty years old [4]. Chemotherapy is a major mode of treatment for various cancers. However, it is usually associated with adverse side effects, ranging from nausea to bone marrow failure [5], and development of multidrug resistance (MDR). Therefore, finding natural compounds from plants may provide an alternative cancer treatment [6].

Zizyphus spina christi, commonly known as Christ's thorn in English and Sidr or Nabqa in Arabic is a tree belonging to the genus Zizyphus in Rhamnaceae family [7]. It has been used in folk medicine as demulcent, emollient, and as a mouth wash [8]. The plant has been reported to possess antioxidant, antibacterial, antifungal, antidiabetic, and analgesic effects [9]. Antioxidant activity and the presence of flavonoids make the plant possible to have anticancer activity. Furthermore, a study done on 2015 approved that methanol extract of Zizyphus spina christi had a potent anti-angiogenic activity and, as angiogenesis is considered one of cancer treatment approaches, methanol extract was appointed to be tested against RD cell line to find out whether this extract has anticancer activity or not. So, the aim of this study was to investigate the capability of Zizyphus spina christi methanol extract to inhibit cancer cell line proliferation.

\section{MATERIALS AND METHODS}

\section{Chemicals and reagents}

The chemicals and reagents used in the study are listed in table (1)

\section{Plant material collection and extraction}

Fresh and healthy leaves of Zizyphus spina christi were collected from various regions of An Nasiriyah city, Iraq. Leaf specimen was labeled and annotated with date of collection and locality. A voucher specimen number (2) was deposited at the College of pharmacy, Baghdad University. The leaves were washed thoroughly under running tap water and oven dried at $40{ }^{\circ} \mathrm{C}$. The dried leaves were then grounded into fine powder using an electric grinder.

The extraction process was performed in the Department of Pharmacology, Al-Nahrain College of Medicine. The dried powdered leaves were extracted by cold maceration method. The powder $(500$ gm) was soaked into methanol, left in a shaking water bath at $40{ }^{\circ} \mathrm{C}$ for $8 \mathrm{~h}$, then filtered through whatman No. 1 filter paper. The filtrate was pooled in an airtight dark bottle to be concentrated to dryness under reduced pressure and low temperature using rotary evaporator. The dried extract was stored in refrigerator until use [10].

Table 1: Chemicals and reagents

\begin{tabular}{ll}
\hline Chemical or reagent & Source \\
\hline Ascorbic acid & Sigma Aldrich, Germany \\
DMSO & Sigma Aldrich, Germany \\
Heat inactivated fetal calf serum (HIFBS) & Sigma-Aldrich, Germany \\
Methanol & Sigma-Aldrich, Germany \\
RD cell line & American Type Culture Collection (ATCC, Rockville, MD, USA), \\
Trypsin EDTA & Sigma Aldrich, Germany \\
1,1-diphenyl-2-picrylhydrazyl (DPPH) & Sigma Aldrich, Germany \\
1\% penicillin/streptomycin & Sigma Aldrich, Germany \\
3-(4,5-Dimethylthiazol-2-yl)-2,5-diphenyltetrazolium bromide (MTT) & Sigma Aldrich, Germany \\
\hline
\end{tabular}


Assessment of anti-proliferative activity of the methanol extract against RD cell line by MTT assay

\section{RD cell line culture and treatment}

This assay was used to investigate the anti-proliferative activity of methanol extract of Zizyphus spina christi leaves against human rhabdomyosarcoma (RD) cell line. The cells were grown on RPMI1640 medium supplemented with: $10 \%$ Heat inactivated fetal calf serum (HIFBS) and $1 \%$ penicillin/streptomycin. The monolayer cells were detached and a single cell suspension was made using trypsin ethylenediamine tetraacetic acid (trypsin EDTA). A hemocytometer was used to count the viable cells number. The cell suspension was diluted with RPMI-1640 medium in order to obtain final density of $1 \times 10^{4} \mathrm{cell} / \mathrm{ml}$. The cells were seeded in 96 wells plate, with 200 $\mu \mathrm{l} /$ well and were maintained in a humidified incubator at $37^{\circ} \mathrm{C}$, in a $5 \% \mathrm{CO}_{2} / 95 \%$ air for $24 \mathrm{~h}$. A stock solution of $1 \%$ of the methanol extract of Zizyphus spina christi in DMSO was prepared. Serial dilutions were prepared by dissolving an appropriate volume of this stock solution in the serum free RPMI-1640 medium and diluting it serially to obtain final concentrations of $100,50,25,12.5$, and 6.25 $\mu \mathrm{g} / \mathrm{ml}$. After $24 \mathrm{~h}$, the cells seeding media was replaced with new media that contain the serial concentrations of the extract and the cells, supplemented with the new media were incubated for further $48 \mathrm{~h}$. $(200 \mu \mathrm{l})$ of each concentration were added to the plate well. Each concentration was tested in 8 replicates ( 8 wells), and the experiment was repeated twice. Serum free media without sample received $1 \%$ of DMSO and served as negative control ( 8 wells)[11].

\section{MTT assay}

After $48 \mathrm{~h}$ of incubation, $150 \mu \mathrm{l}$ of the exposure media was removed from the wells and $50 \mu \mathrm{l}$ of MTT in phosphate buffered saline 0.4 $\mathrm{mg} / \mathrm{ml}$ ) was added to each well and incubated for $4 \mathrm{~h}$. After that, the medium with MTT was flicked off and the formed formazan crystals were solubilized in $100 \mu \mathrm{l}$ of DMSO at $37^{\circ} \mathrm{C}$ for $2 \mathrm{~h}$. The absorbance was measured at $570 \mathrm{~nm}$ using ELISA plate reader. The percentage of cell growth inhibition was determined using the following formula:

$\%$ of inhibition $\left[\left(\mathrm{A}_{\mathrm{C}}-\mathrm{A}_{\mathrm{S}}\right) / \mathrm{A}_{\mathrm{C}}\right] \times 100 \%$ Where:

As: Absorbance of the sample Ac: Absorbance of the control [11].

Gas chromatography-mass spectrometry (GC-MS) analysis of bioactive compounds in the methanol extract

The Gas Chromatography-Mass Spectrometry (GC-MS) analysis of methanol extract of Zizyphus spina christi was performed using a GCMS (Model; QP 2010S, Japan). (1 $\mu$ l) of the methanol extract was injected with a Hamilton syringe to the GC-MS manually for total ion chromatographic analysis in split injection technique. The bioactive compounds of the extract were identified by comparing their retention index and patterns of mass spectra with reference to Wiley Registry of Mass Spectral Data"s, New York (Wiley 8) and Fatty Acid Methyl Esters Library version 1.0 (FAME library) sources [12].

\section{DPPH scavenging activity assay}

The antioxidant activity of methanol extract of Zizyphus spina christi was assessed by measuring free radical scavenging activity using DPPH method. Serial dilutions of the methanol extract in methanol were prepared with the following concentrations: 500, 250, 125, $62.5,31.25,15.62$ and $7.8 \mu \mathrm{g} / \mathrm{ml}$. (1 ml) of $0.1 \mathrm{mmol}$ solution of DPPH in methanol was added to $2 \mathrm{ml}$ of each dilution of the extract. Ascorbic acid, which is a well-known antioxidant; was used as positive control. DPPH solution in the absence of the extract was used as control and methanol was used as blank. All the tests were performed in triplicate. After half hour of incubation in dark, absorbance was measured at $490 \mathrm{~nm}$ using ELISA plate reader.

The percentage of DPPH scavenging activity (P) was calculated using the following formula:

$$
P=\left[\left(A_{0}-A s\right) / A_{0}\right] \times 100 \%
$$

Where:

$A_{0}$ : Absorbance of the control.

As: Absorbance of the sample.

The $\mathrm{IC}_{50}$, which is the concentration required to scavenge $50 \%$ of DPPH free radical, was calculated using dose inhibition curve by plotting the sample concentration versus the corresponding DPPH scavenging activity[13].

\section{RESULTS}

\section{Amount of Zizyphus spina christi leaves crude extract}

The amount obtained from the extraction of $500 \mathrm{~g}$ of leaves powder was $103.2 \mathrm{~g}$, the percent yield was $20.64 \%$.

\section{Anti-proliferative activity of the methanol extract against RD cell line}

The percentages of cell growth inhibition were presented as mean \pm SD (table 2). The results showed that all the tested concentrations of the methanol extract significantly inhibited RD cell line growth after $48 \mathrm{~h}(P<0.05)$. The inhibition was dose dependent. $\mathrm{IC}_{50}$ was calculated from the following logarithmic regression equation:

$\mathrm{y}$ Q $4.2329 \ln (\mathrm{x})+28.667$, and was equal to $154.44 \mu \mathrm{g} / \mathrm{ml}$.

Where: $\mathrm{x}=$ Concentration, $\mathrm{y}$ ? The percentage of inhibition.

Table 2: Percentages of cell growth inhibition of methanol extract of Zizyphus spina christi leaves on human rhabdomyosarcoma (RD) cell line by MTT assay

\begin{tabular}{ll}
\hline Concentration $(\mu \mathrm{g} / \mathrm{ml})$ & Mean inhibition $(\%) \pm$ SD \\
\hline 6.25 & $37.8 \pm 0.047^{*}$ \\
12.5 & $38.34 \pm 0.045^{*}$ \\
25 & $40.46 \pm 0.037^{*}$ \\
50 & $46.44 \pm 0.042^{*}$ \\
100 & $48.42 \pm 0.024^{*}$ \\
\hline
\end{tabular}

$*=$ Statistically significant difference compared with the negative control $(P<0.05)$.

\section{Bioactive compounds in the methanol extract identified by GC- MS analysis}

Twenty-eight compounds were identified in methanol extract of Zizyphus spina christi leaves (fig. 1). The major compounds identified in the extract which could explain the antioxidant and antiproliferative activity were [4H-Pyran-4-one, 2,3-dihydro-3,5dihydroxy-6-methyl-] (flavonoid fraction) (Line: 8), n-Hexadecanoic acid (saturated fatty acid) (Line: 21) and [2,4-Dihydroxy-2,5dimethyl-3(2H)-furan-3-one] (Line: 6).

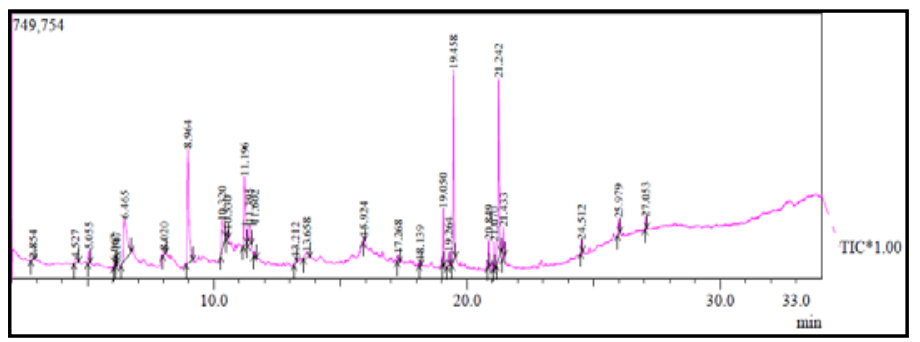

Fig. 1: Gas chromatography-mass spectrometry (GC-MS) chromatogram of methanol extract of Zizyphus spina christi leaves 


\section{DPPH scavenging activity}

The results showed that DPPH scavenging activities of ascorbic acid and methanol extract of Zizyphus spina christi leaves were dose dependent. The $\mathrm{IC}_{50}$ values of $\mathrm{DPPH}$ scavenging activity were calculated using the following logarithmic regression equations:

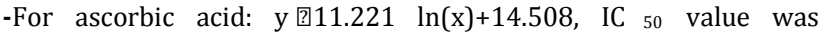
23.64 $\mu \mathrm{g} / \mathrm{ml}$ (fig. 2).

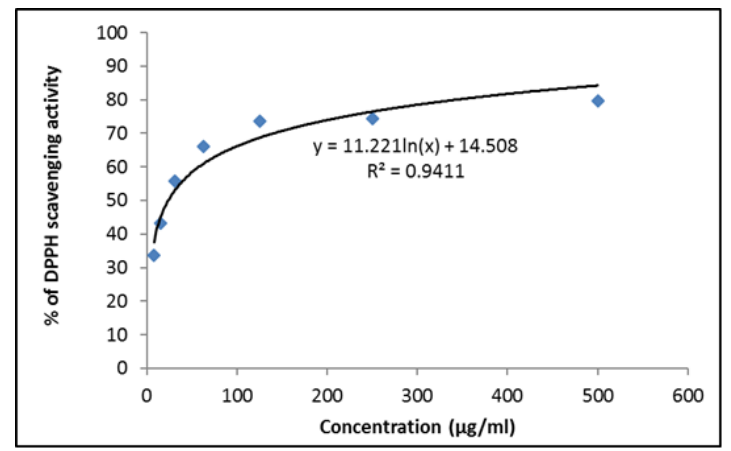

Fig. 2: 1,1-diphenyl-2-picrylhydrazyl (DPPH) scavenging activity of serial dilutions of ascorbic acid

-For methanol extract: $\mathrm{y}$ ? $12.913 \ln (\mathrm{x})+4.4977$, IC 50 value was 33.91 $\mu \mathrm{g} / \mathrm{ml}$ (fig. 3).

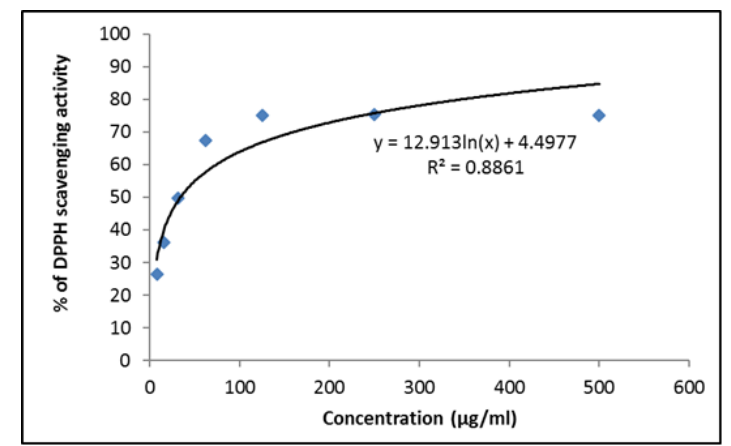

Fig. 3: 1,1-diphenyl-2-picrylhydrazyl (DPPH) scavenging activity of serial dilutions of Zizyphus spina christi leaves methanol extract

Where:

y ? Percentage of DPPH scavenging activity and is set at $50 \%$,

$\mathrm{x}$ ? concentration.

\section{DISCUSSION}

The extraction process used in this study was cold maceration method. This method is suitable for extraction of thermo-liable compounds since high temperature may cause destruction of these compounds [14]. The leaves of Zizyphus spina christi were washed, dried and grinded before maceration. Grinding helps in getting a homogenous sample and increasing the contact area of the sample with the solvent system [15].

The anti-proliferative activity of potential antitumor agents was assessed by many experimental models, including the in vivo assays such as transplanted tumors [16, 17] and chemically induced malignancies [18]; or in vitro screening models. Among various in vitro models, the MTT assay, first described by Mosmann as a fastcolorimetric assay was selected as valid, easy, and semiautomated method for assessing growth inhibition in established cell lines [19].
A previous study showed that methanol extract of Zizyphus spina christi has a potent anti-angiogenic activity [20]. Since antiangiogenic agents may have antitumor activity, it is wise to investigate the cytotoxic activity of methanol extract of Zizyphus spina christi on a tumor cell line. In the present study, the in vitro cytotoxic activity of methanol extract of Zizyphus spina christi was evaluated using human RD cell line. The results showed that all the tested concentrations of methanol extract of Zizyphus spina christi leaves exerted significant anti-proliferative activity against RD cell line after $48 \mathrm{~h}$ of treatment compared to negative control. The inhibition was concentration dependent and $\mathrm{IC}_{50}$ value was 154.44 $\mu \mathrm{g} / \mathrm{ml}$. According to United States National Cancer Institute plant screening program, a plant extract is generally considered cytotoxic if $\mathrm{IC}_{50}$ value, following incubation period between 48 to $72 \mathrm{~h}$; is 20 $\mu \mathrm{g} / \mathrm{ml}$ or less [21]. So, the extract has anti-proliferative but no cytotoxic activity against RD cell line.

The GC-MS spectroscopy of the methanol extract showed the presence of (4H-Pyran-4-one, 2,3-dihydro-3,5-dihydroxy-6-methyl-), which is a flavonoid fraction. Flavonoids significantly influence the cascade of immunological events associated with the cancer development and progression [22]. Many in vivo and in vitro studies showed that flavonoids may inhibit various stages in the carcinogenesis process, including tumor initiation, promotion and progression by many mechanisms of action, which may include inactivation of carcinogens, anti-proliferative action, cell cycle arrest, induction of apoptosis, anti-angiogenic action, reversal of multidrug resistance, antioxidant action or a combination of these mechanisms [23]. The other major compounds identified in the extract analyzed by GC-MS spectroscopy were: n-hexadecanoic acid and $[2,4$ Dihydroxy-2,5dimethyl-3(2H)-furan-3-one]. N-hexadecanoic acid has been reported to possess antioxidant, anti-inflammatory and antitumor activity [24-26]. It was demonstrated that n-hexadecanoic acid exert anti-inflammatory activity through competitive inhibition of phospholipase $A_{2}$ [27]. Phospholipase $A_{2}$ has a critical role in angiogenesis, tumorigenesis and tumor metastasis [28,29]. [2,4Dihydroxy-2,5-dimethyl-3(2H)-furan-3one] has been reported to possess antioxidant and anti-inflammatory activity [30].

The DPPH assay is based on the measurement of the scavenging capacity of antioxidants towards the stable free radical, DPPH. When DPPH solution is mixed with antioxidant, the odd electron of nitrogen atom in DPPH is reduced to the corresponding hydrazine by receiving a hydrogen atom from the antioxidant compound with the loss of violet color [31]. Free radicals are chemical species that contain unpaired electrons [32]. They are produced in biological systems and exogenously, and are known to cause various degenerative disorders, like mutagenesis, carcinogenesis, cardiovascular disturbances and aging [33].

In this study, the methanol extract showed good antioxidant activity (in terms of DPPH scavenging activity). This agree with previous studies in which methanol was the most efficient solvent for extraction of antioxidant compounds, particularly phenolic compounds [34-36]. Phenolic compounds, such as flavonoids; possess many biological effects, mostly attributed to their antioxidant activities [37]. The mechanisms of antioxidant action of flavonoids can include: (1) Inhibition of ROS formation either by chelating trace elements or by inhibition of enzymes involved in free radical generation; (2) Scavenging ROS; and (3) Up-regulation of antioxidant defenses [38, 39].

The inhibitory effect of methanol extract of Zizyphus spina christi on RD cell line could be due to its antioxidant activity. Antioxidants are thought to prevent the initiation step of carcinogenesis, mainly due to their capacity to protect cells from the damage induced by free radicals. Damage to DNA by reactive oxygen species (ROS) has been widely accepted as a major cause of cancer $[40,41]$.

\section{CONCLUSION}

Methanol extract of Zizyphus spina christi showed no cytotoxic activity against RD cell line. However, the data showed a dose related inhibitory activity against RD cell line; which could be attributed to the antioxidant activity of the methanol extract as shown in DPPH assay. Furthermore, the GC-MS analysis showed 
the presence of compounds with antiproliferative activity (eg, flavonoids).

\section{CONFLICTS OF INTERESTS}

Declared none

\section{REFERENCES}

1. Lopez-Gomez M, Malmierca E, de Gorgolas M, Casado E. Cancer in developing countries: the next most preventable pandemic. The global problem of cancer. Crit Rev Oncol Hematol 2013;88:117-22.

2. American Cancer Society. Cancer Facts and fig. 2012. Atlanta: American Cancer Society.

3. Saab R, Spunt SL, Skapek SX. Myogenesis and rhabdomyosarcoma the Jekyll and Hyde of skeletal muscle. Curr Top Dev Biol 2011;94:197-234.

4. Ognjanovic S, Linabery AM, Charbonneau B, Ross JA. Trends in childhood rhabdomyosarcoma incidence and survival in the United States, 1975-2005. Cancer 2009;115(18):4218-26.

5. Cancer Research UK. Side Effects of Cancer Drugs. Available online: http://cancerhelp. cancerresearchuk. Org/aboutcancer/treatment/cancer-drugs/side-effects (accessed on 14 February 2013).

6. Raguz, S, YagueE. Resistance to chemotherapy: New treatments and novel insights into an old problem. Br. J. Cancer 2008;99:387-91.

7. Yossef HE, Khedr AA, Mahran MZ. Hepatoprotective activity and antioxidant effects of El Nabka (Zizyphus spina christi) fruits on rat hepatotoxicity induced by carbon tetrachloride. Nat. Sci 2011;9:17.

8. Duke JA. Handbook of Medical Herbs. CRC Press: Boca Raton; 1985.

9. Asgarpanah J, Haghigat E. Phytochemistry and pharmacologic properties of Ziziphus spina christi (L.) Willd. Afr J Pharm Pharmacol 2012;6:2332-9.

10. Pathmanathan MK, Uthayarasa K, Jeyadevan JP, Jeyaseelan EC. In vitro antibacterial activity and phytochemical analysis of some selected medicinal plants. Int J Pharm Biol Arch 2010;1:291-9.

11. Mosmann T. Rapid colorimetric assay for cellular growth and survival: application to proliferation and cytotoxicity assays. J Immunol Methods 1983;65:55-63.

12. Mujeeb F, Bajpai P, Pathak N. Phytochemical evaluation, antimicrobial activity and determination of bioactive components from leaves of aegle marmelos. BioMed Res Int 2014;1-11. http://dx.doi.org/10.1155/2014/497606.

13. Oktay M, Gulcin I, Kufrevioglu OI. Determination of in vitro antioxidant activity of funnel (Foeniculum vulgare) seed extracts. Lebensm-Wiss U-Technoli 2003;36:263-71.

14. Shams KA, Abdel-Azim NS, Saleh IA. Green technology: economically and environmentally innovative methods for extraction of medicinal andaromatic plants (MAP) in Egypt. J Chem Pharm Res 2015;7:1050-74.

15. Sasidharan S, Chen Y, Saravanan D, Sundram KM, Yoga Latha L. Extraction, isolation and characterization of bioactive compounds from plants' Extracts. Afr J Traditional Complementary Alternative Med 2011;8:1-10.

16. Goldin A, Venditti JM, MacDonald JS. Current results of the screening program at the division of cancer treatment, National Cancer Institute. Eur J Cancer 1981;17:129-42.

17. Venditti JM. Preclinical drug development: rationale and methods. Semin Oncol 1981;8:349-61.

18. Schmahl D, Berger MR. Possibilities and limitations of antineoplastic chemotherapy: experimental and clinical aspects. Int J Exp Clin Chemother 1988;1:1-11.

19. Scudiero DA, Shoemaker RH, Paull KD. Evaluation of a soluble tetrazolium/formazan assay for cell growth and drug sensitivity in culture using human and other tumor cell lines. Cancer Res 1988;48:4827-33.
20. Ahmed R Abu-Raghif, Hayder B Sahib, Muneer M Hanoon. Antiangiogenic activity of Zizyphus spina christi Leaves Extracts. Int J Pharm Sci Rev Res 2015;35:169-74.

21. Vijayarathna S, Sasidharan S. Cytotoxicity of methanol extracts of Elaeis guineensis on MCF-7 and Vero cell lines. Asian Pac J Trop Biomed 2012;2:826-9.

22. Batra P, Sharma AK. Anti-cancer potential of flavonoids: recent trends and future perspectives. Biotechnology 2013;3:439-59.

23. Ren W, Qiao Z, Wang H, Zhu L, Zhang L. Flavonoids: promising anticancer agents. Med Res Rev 2003;23:519-34.

24. Harada H, Yamashita U, Kurihara H. Antitumor activity of palmitic acid found as a selective cytotoxic substance in a marine red alga. Anticancer Res 2002;22:2587-90.

25. Sermakkani M, Thangapandian V. gc-ms analysis of Cassia italica leaf methanol extract. Asian J Pharm Clin Res 2012;5:90-4.

26. Gopalakrishnan K, Udayakumar R. GC-MS analysis of phytocompounds of Leaf and Stem of Marsilea quadrifolia (L.). Int J Biochem Res Rev 2014;4:517-26.

27. Aparna V, Dileep KV, Mandal PK. Antilnflammatory property of n-hexadecanoic acid: structural evidence and kinetic assessment. Chem Biol Drug Des 2012;80:434-9.

28. Jeong WC, Kim KJ, Ju H. Cytoplasmic phospholipase $A_{2}$ metabolites play a critical role in pulmonary tumor metastasis in mice. Anticancer Res 2010;30:3421-7.

29. Linkous AG, Yazlovitskaya EM, Hallahan DE. Cytosolic phospholipase $\mathrm{A}_{2}$ and lysophospholipids in tumor angiogenesis. J Natr Cancer Inst 2010;102:1398-412.

30. Chidambaram V, Niraimathi L, Sudha V. Spectrophotometric, HPTLC and GC-MS studies on selected spice extracts. Int J Pharm Pharm Sci 2015;7:184-90.

31. Kedare SB, Singh RP. Genesis and development of DPPH method of antioxidant assay. J Food Sci Technol 2011;48: 412-22.

32. Pryor WA, Houk KN, Foote CS. Free radical biology and medicine: it"s a gas, man! Am J Physiol: Regul Integr Comp Physiol 2006;291:491-511.

33. Singh S, Singh RP. In vitro methods of assay of antioxidants: an overview. Food Rev Int 2008;24:392-415.

34. Al-Jassabi S, Abdullah MS. Extraction, purification and characterization of antioxidant fractions from Zizyphus spinachristi fruits. Am-Eur J Toxicol Sci 2013;5:66-71.

35. Boeing JS, Barizaol EO, Silva CS, Montanher PF, Almeida VC, Visentainer JV. Evaluation of solvent effect on the extraction of phenolic compounds and antioxidant capacities from the berries: application of principal component analysis. Chem Central J 2014;8:48.

36. Khaleel. Evaluation of total phenolic content and antioxidant activity of three leaf extracts of Ziziphus spina-christi (Sedr) Grown in Jordan. Br J Med Med Res 2016;14:1-8.

37. Brum TF, Zadra M, Piana M. HPLC analysis of phenolics compounds and antioxidant capacity of leaves of Vitex megapotamica (Sprengel) Moldenke. Molecules 2013;18: 8342-57.

38. Halliwell B, Gutteridge JMC. Free radicals in biology and medicine. 3rd edition. Clarendon Press: Oxford, UK; 1999.

39. Mishra A, Kumar S, Pandey AK. Scientific validation of the medicinal efficacy of Tinospora cordifolia. Sci World J 2013. http://dx.doi.org/10.1155/2013/292934

40. Aruoma OI. Nutrition and health aspects of free radicals and antioxidants. Food Chem Toxicol 1994;32:671-83.

41. Fang YZ, Yang $\mathrm{S}, \mathrm{Wu}$ G. Free radicals, antioxidants, and nutrition. Nutrition 2002;18:872-9.

\section{How to cite this article}

- $\quad$ Ahmed R Abu-Raghif, Ghaith A Jasim, Muneer M Hanoon. Antiproliferative activity of Zizyphus spina christi leaves methanol extract against rhabdomyosarcoma (RD) cell Line. Int J Pharm Pharm Sci 2017;9(2):279-282. 